PROFESIONALES Y HERRAMIENTAS PARA EL DESARROLLO LOCAL Y SUS SINERGIAS TERRITORIALES. EVALUACIÓN Y PROPUESTAS DE FUTURO IX Coloquio Nacional de Desarrollo Local del GTDL-AGE 

ANTONIO MARTÍNEZ PUCHE, XAVIER AMAT MONTESINOS, ISABEL SANCHO CARBONELL y DANIEL SANCHIZ CASTAÑO (EDS.)

\section{PROFESIONALES Y HERRAMIENTAS PARA EL DESARROLLO LOCAL Y SUS SINERGIAS TERRITORIALES. EVALUACIÓN Y PROPUESTAS DE FUTURO}

IX Coloquio Nacional de Desarrollo Local del GTDL-AGE

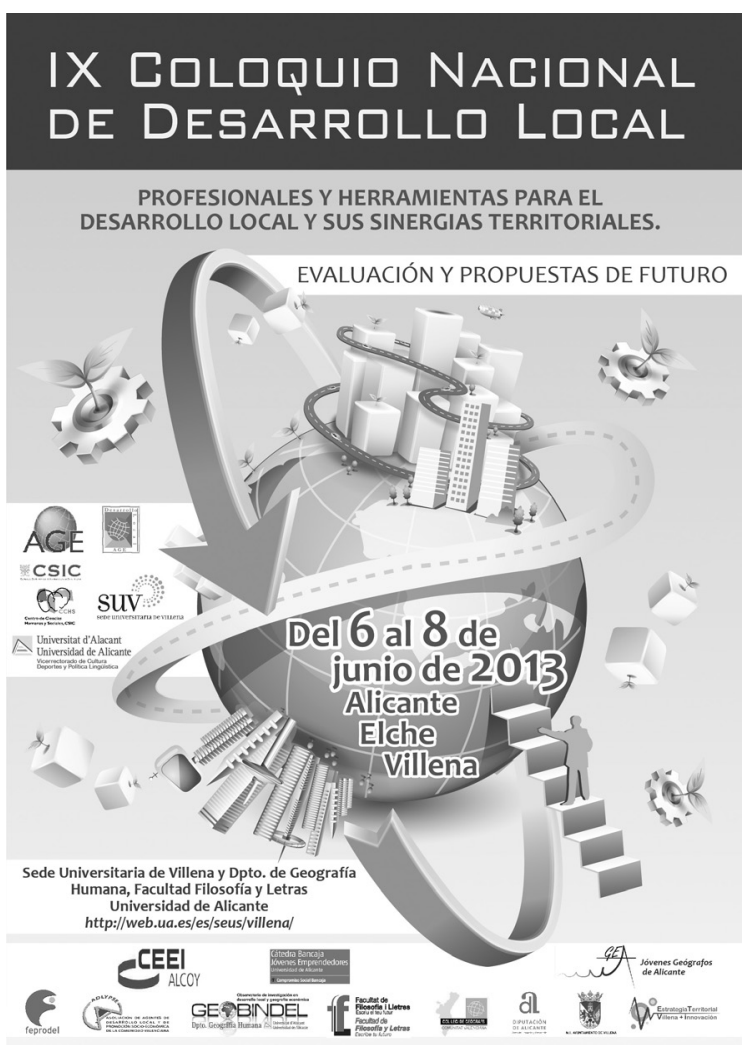


Este libro ha sido examinado y valorado por evaluadores ajenos a la Universidad de Alicante, con el fin de garantizar la calidad científica del mismo.

Publicacions de la Universitat d'Alacant

03690 Sant Vicent del Raspeig

Publicaciones@ua.es

http://publicaciones.ua.es

Telèfon: 965903480

(C) Antonio Martínez Puche, Xavier Amat Montesinos,

Isabel Sancho Carbonell y Daniel Sanchiz Castaño (eds.), 2016

(C) d'aquesta edició: Universitat d'Alacant

ISBN: 978-84-16724-00-0

Dipòsit legal: A 92-2016

Disseny de coberta: candela ink

Composició: Página Maestra (Miguel Ángel Sánchez Hernández)

Impressió i enquadernació: Guada Impresores

\section{unte \\ Unión de Editoriales
Universitarias Españolas \\ WWW.une.es
WWA}

Esta editorial es miembro de la UNE, cosa que garantiza la difusión y comercialización nacional y internacional de sus publicaciones.

Reservados todos los derechos. Cualquier forma de reproducción, distribución, comunicación pública o transformación de esta obra sólo puede ser realizada con la autorización de sus titulares, salvo excepción prevista por la ley. Diríjase a CEDRO (Centro Español de Derechos Repográficos, www.cedro.org) si necesita fotocopias o escanear algún fragmento de esta obra. 


\title{
IMPULSO AL DESARROLLO LOCAL EN EL DIARIO 'LA OPINIÓN-EL CORREO DE ZAMORA'. COMARCAS DE ALISTE, TÁBARA Y ALBA
}

\author{
Antonio Teruel García \\ Periodista - Diario Información (Alicante) \\ Máster en Desarrollo Local e Innovación Territorial (Universidad de Alicante) \\ jof4@alu.ua.es
}

\section{RESUMEN}

Los medios de comunicación de proximidad pueden hacer una aportación destacada al desarrollo local, al ejercer como difusores de la actividad que se produce en un territorio y contribuir a potenciar sus elementos socioeconómicos y culturales. En las comunidades más pequeñas, esta promoción de los rasgos identitarios contribuye a la cohesión social, y favorece la implicación ciudadana en las políticas encaminadas a fomentar ese desarrollo.

Así, la divulgación del día a día del territorio, de sus valores y de sus problemas, puede espolear la conciencia colectiva y fortalecer las acciones dirigidas a la mejora de las condiciones económicas, sociales y culturales. El diario La Opinión-El Correo de Zamora realiza este papel en las comarcas de Aliste, Tábara y Alba, situadas en la zona occidental de esa demarcación castellanoleonesa, lindando con Portugal. Las tres conforman un territorio que reproduce, a una escala aún mayor, los problemas más graves que viene sufriendo toda la provincia de Zamora desde mediados del siglo XX. Se trata de un lugar duramente lastrado por la despoblación y el envejecimiento, con una densidad de apenas 7 habitantes por kilómetro cuadrado, y que secularmente se ha visto sometido al olvido por su distancia respecto a otras zonas más habitadas y con un mayor dinamismo económico. El periódico recoge en sus páginas la cotidianeidad de estas comarcas, plasmando su potencial humano, cultural y económico, así como los problemas a los que se enfrenta. De alguna forma, el diario hace posible que todos los lectores sepan que Aliste, Tábara y Alba existen, y que sus propios habitantes sean conscientes de las posibilidades que tienen a su alcance. 
Las condiciones de vida de los pueblos, las tradiciones ancestrales, la puesta en marcha de iniciativas emprendedoras, la cooperación transfronteriza y la divulgación de los recursos naturales de Aliste, Tábara y Alba son algunos de los temas que tienen un reflejo diario en La Opinión-El Correo de Zamora. El periódico es consciente de la importancia de incidir en esta labor, tanto por la perspectiva empresarial de fidelizar lectores como por el empeño de mostrar y reivindicar los intereses de una tierra que ha padecido históricamente las consecuencias de ser un territorio periférico. La sociedad local está respondiendo de una forma muy positiva, tal y como indican las cifras de difusión del periódico -muy elevadas, teniendo en cuenta la escasa población y el delicado momento que vive la prensa escrita- y la percepción que existe acerca de la importancia de este medio de comunicación para situarse en el mapa y, de esta forma, hacer que se conozcan todas las acciones de desarrollo local que se llevan a cabo.

Palabras clave: La Opinión-El Correo de Zamora, medios de comunicación, recursos territoriales, despoblación.

\section{IMPEL TO THE LOCAL DEVELOPMENT IN THE NEWSPAPER 'THE OPINION-THE MAIL DE ZAMORA.' DISTRICTS OF ALISTE, TÁBARA AND ALBA}

\section{ABSTRACT}

The media of vicinity can make an outstanding contribution to the local development, when exercising as difusores of the activity that takes place in a territory and to contribute to develop its socioeconomic and cultural elements. In the smallest communities, this promotion of the features contributes to the social cohesion, and it favors the civic implication in the politicians guided to foment that development. This way, the popularization of the day by day of the territory, of their values and of their problems, it can spur the collective conscience and to strengthen the actions directed to the improvement of the economic, social and cultural conditions. The newspaper The Zamora's Mail carries out this paper in the districts of it Enlists, Tábara and Alba, located in the western area of that demarcation Castilian-leonesa, abutting with Portugal. The three conform a territory that reproduces, to an even bigger scale, the most serious problems that it comes suffering Zamora's county from half-filled of the XX century. It is about a place difficultly ballasted by the depopulation and the aging, with a density of hardly 7 inhabitants for square kilometer, and that secularly it has been subjected to the forgetfulness for their distance regarding other more inhabited areas and with an economic bigger dynamism. The newspaper picks up in its pages the day-to-dayness of these districts, capturing its human, cultural and economic potential, as well as the problems to those that he/she 
faces. In some way, the newspaper makes possible that all the readers know that Aliste, Tábara and Alba exist, and that their own inhabitants are aware of the possibilities that have within its reach.

Keywords: The Review-Courier Zamora, media, territorial resources, depopulation.

\section{INTRODUCCIÓN}

El diario La Opinión-El Correo de Zamora es un caso muy singular en el tratamiento de la información local y comarcal, al margen de la de la capital, tanto por el espacio que le concede como por el enfoque de los contenidos. Pese a tratarse de una provincia muy poco poblada, muy envejecida y sin apenas núcleos urbanos importantes, el periódico presta mucha importancia a las noticias generadas en los pueblos, haciéndose eco de su actualidad, sus problemas y demandas y su idiosincrasia. Estos temas se abordan como el reflejo constante de una realidad y no como una anécdota.

El fenómeno de La Opinión-El Correo de Zamora no ha sido estudiado todavía, por lo que consideramos que merece ser abordado con profundidad ${ }^{1}$. Estimamos que el periódico realiza, desde su posición, una función de desarrollo territorial en la provincia de Zamora, mediante la difusión diaria de la actualidad de sus pueblos y comarcas, así como su situación socioeconómica, sus aspiraciones y reivindicaciones y sus posibilidades de dinamismo en distintos ámbitos. Esta comunicación se centra en el entorno conformado por las comarcas naturales de Aliste, Tábara y Alba, al oeste de la demarcación zamorana, que entendemos como un ejemplo paradigmático de cómo se contribuye desde el diario al desarrollo de un territorio determinado.

\section{El territorio: Aliste, TÁbara y Alba}

Las comarcas zamoranas de Aliste, Tábara y Alba conforman una unidad territorial $^{2}$ con unas características demográficas y socioeconómicas muy particulares, con la escasez de población, el envejecimiento, la falta de una red urbana consolidada, la inactividad, el relativo atraso y el olvido como factores

1 En el curso académico 2012-2013 hemos afrontado la realización de un Trabajo de Fin de Máster en la Universidad de Alicante titulado Impulso al desarrollo local en el diario 'La Opinión-El Correo de Zamora'. El caso de Aliste, Tábara y Alba, del cual esta comunicación fue un primer esbozo y del que finalmente ha terminado por convertirse en un resumen. Nuestra intención es seguir profundizando en la investigación sobre la interacción entre este periódico y la sociedad de la provincia de Zamora.

2 Hay ciertas vacilaciones en la delimitación de estas comarcas, en función del autor. En esta comunicación, el ámbito territorial analizado se corresponde con los municipios integrados en el Grupo de Acción Local Asociación para el Desarrollo de Aliste, Tábara y Alba, < $<$ ttp:// www.adata.es> [Fecha de consulta: 12 de febrero de 2013]. 
principales. Todo ello se da también, no obstante, en el conjunto de la provincia de Zamora, donde el vacío demográfico y la avanzada edad de sus pocos habitantes son un problema de primera magnitud.

\subsection{El contexto: despoblación y envejecimiento en la provincia de Zamora}

Con una extensión de 10.561 kilómetros cuadrados y una población de sólo 191.612 habitantes ${ }^{3}$, la provincia de Zamora tiene una densidad de 18,14 habitantes por kilómetro cuadrado, la quinta más baja de toda España. La cifra actual de empadronados es casi un $40 \%$ inferior a la de 1950, cuando se registró el máximo demográfico a lo largo del último siglo. Entonces habitaban la provincia 316.493 personas, pero desde la citada fecha y, sobre todo, a partir de 1960, se produjo una fuerte emigración hacia otras zonas de España más industrializadas y a otros países europeos ${ }^{4}$. El declive se mantiene en la actualidad; desde 2002 se han perdido 9.066 habitantes, un $4,52 \%$.

La consecuencia de más de 60 años de sangría demográfica ininterrumpida no es sólo que la población sea muy escasa, sino que además esté muy envejecida. La edad media de los zamoranos es la segunda más avanzada de toda España -por detrás tan sólo de Ourense-, con 47,3 años para los hombres y 50,3 en el caso de las mujeres. La tasa de vejez alcanza el $28,74 \%$; en la provincia residen 55.074 personas con 65 años y más. Paralelamente, se ha dado un proceso de masculinización de la población, ya que buena parte de la emigración ha sido femenina. La proporción de mujeres adultas-jóvenes es particularmente baja ${ }^{5}$, lo que dificulta aún más el reemplazo generacional.

A estos factores hay que añadir el de la elevada ruralidad. La ciudad de Zamora, con apenas 65.000 habitantes y una economía basada en el comercio y los servicios, no tiene poder de atracción más allá de los límites provinciales ${ }^{6}$. $\mathrm{Su}$ crecimiento ha sido lento en las últimas décadas e, incluso, en la actualidad su población está estancada. Además, queda eclipsada por ciudades de mayor tamaño y de actividades más diversas muy próximas, como Salamanca y Valladolid. Fuera de la capital, en toda la provincia sólo sobresalen Benavente (19.000 habitantes) y Toro (9.000). La provincia cuenta con 248 municipios, de los cuales sólo 20 sobrepasan el millar de habitantes.

3 Dato oficial del Padrón de Habitantes a 1 de enero de 2012. Fuente: Instituto Nacional de Estadística, <www.ine.es> [Fecha de consulta: 15 de mayo de 2013]. Todos los datos demográficos proceden de la misma fuente, salvo cita expresa.

4 MAYA FRADES, Valentina: La mujer rural en la provincia de Zamora. Salamanca, Fondo Social Europeo-Diputación de Zamora-Ministerio de Administraciones Públicas-Atalanta (Promoción de de Empleo para la Mujer Rural), 2004, p. 49.

5 Ibídem., pp. 51-54.

6 SÁNCHEZ ZURRO, Domingo: Geografía de Castilla y León. Valladolid, Junta de Castilla y León-Ámbito ediciones, 2008, pp. 218-220. 
Todos estos datos configuran un panorama poco alentador, agravado por una cierta percepción social de que se trata de un lugar estático y átono, sin atractivos ni perspectivas de futuro. Entre la población se han instalado el pesimismo y la apatía, tal y como señala el sociólogo José Manuel del Barrio, colaborador habitual de La Opinión-El Correo de Zamora. Ya en 2002, el autor achacaba esto a la propagación de "imágenes falsas y errores de bulto" entre los propios zamoranos. Citaba, entre otros prejuicios -hasta $23-$, la creencia de que la provincia carece de recursos endógenos y es víctima de agravios comparativos, poniendo todos ellos en entredicho ${ }^{7}$ y apelando a invertir este conformismo y esta negatividad social devolviendo al medio rural el protagonismo perdido, poniendo en valor de los elementos de la cultura tradicional desde el turismo o la curiosidad colectiva ${ }^{8}$.

\subsection{El vacío demográfico de Aliste, Tábara y Alba}

El espacio de Aliste, Tábara y Alba -al que es habitual referirse simplemente como Aliste- ocupa 2.105 kilómetros cuadrados al oeste de Zamora, lindando con Portugal. Está habitado por sólo 14.476 personas, con lo que presenta una alarmante densidad de 6,88 habitantes por kilómetro cuadrado. La pérdida de población en el último medio siglo ha sido del $65 \%$, y la tasa de vejez se sitúa en un $43,2 \%$; es decir, casi la mitad de quienes viven en estas comarcas tienen más de 64 años.

El territorio se divide en 31 municipios, de los cuales sólo dos sobrepasan, y por poco, el millar de vecinos: Alcañices (1.207) y Trabazos (1.012). La mayoría de los ayuntamientos cuentan con más de una entidad de población; la comarca tiene un total de 102 núcleos, lo que da una idea del elevado grado de dispersión de los pocos habitantes. El único lugar que concentra más de 1.000 personas es Alcañices, que ejerce de cabecera comarcal pese a su exiguo tamaño. Dispone, entre otros servicios, de instituto de Enseñanza Secundaria y centro de salud ${ }^{9}$, aparte de diversas oficinas bancarias y un mínimo comercio especializado. También, al haber sido cabecera de partido judicial hasta $1966^{10}$, mantiene todavía una notaría y Registro de la Propiedad. Incluso, dada la cercanía de Portugal, cuenta con dependencias de la Policía Nacional ${ }^{11}$. Todo esto hace que Alcañices sea un punto de cierta actividad en un territorio que se halla

7 DEL BARRIO ALISTE, José Manuel: Voces desde el oeste. Una radiografía provocadora de Zamora y sus gentes. Zamora, Monte Casino, 2002, pp. 58-86.

8 Ibídem., pp. 104-105.

9 La vida en la frontera con Portugal. Valladolid, Dirección General de Estadística de la Junta de Castilla y León, 2010, pp. 306 y 330. Edición electrónica descargable en <www.jcyl.es/ estadistica> [Fecha de consulta: 4 de junio de 2013].

10 Boletín Oficial del Estado (24-1-1966), p. 823.

$11<$ http://www.policia.es/org periferica/jsp cast leon/historia.html> [Fecha de consulta: 6 de agosto de 2013]. 
prácticamente vacío, aunque las escasas dimensiones de la localidad hacen que todo esto quede en poco menos que un espejismo. Tras ella, los principales núcleos son Tábara (838 habitantes) y Carbajales de Alba (634), cabeceras respectivas de subcomarca. De los 102 pueblos, 48 tienen menos de 100 vecinos.

La escasez, el envejecimiento y la dispersión de la población por un territorio muy vasto se unen al factor de la ubicación, lejos de grandes centros urbanos y en la frontera con Portugal, y al atraso económico que hasta fecha muy reciente ha sumido históricamente a esta zona en un notable aislamiento. Esto ha hecho que pervivan unas características sociales y culturales muy particulares, recogidas en estudios geográficos y etnográficos y que también se reflejan de manera habitual en la prensa.

\subsection{Aislamiento secular por una ubicación marginal y malas comunicaciones}

Aliste se halla en un entorno físico de penillanura, es decir, presenta un terreno ondulado. Las distintas zonas de Castilla y León con este relieve presentan algunas diferencias entre sí, pero todas ellas coinciden por su escaso hábitat, inferior a los 10 habitantes por kilómetro cuadrado, y por considerarse "marginales" desde el punto de vista de la ubicación y el grado de desarrollo de su economía. Aliste es, precisamente, el "más deprimido" de estos entornos ${ }^{12}$. El suelo está conformado por materiales duros, que dificultan la agricultura y han dado lugar a una ganadería extensiva y a prácticas de explotación comunal de la tierra ${ }^{13}$. Este sistema entró en declive hacia 1960, siendo ya "residual" apenas 30 años después, aunque manteniéndose para el aprovechamiento de prados y bosques en municipios como Alcañices, Fonfría y Rabanales ${ }^{14}$. También está muy relacionada con esta cuestión la elevada parcelación de la tierra.

La dificultad en las comunicaciones ha sido también un lastre histórico en la zona. Aún en 1978, el municipio de Vegalatrave carecía de servicio telefónico y el Ayuntamiento optó por pedir a la Diputación Provincial que mediara para que lo instalaran ${ }^{15}$. En esos mismos años se emitieron varios escritos similares desde otros pueblos a las instituciones de la época, solicitando la construcción de carreteras, la instalación de agua potable o alcantarillado o,

12 SÁNCHEZ ZURRO, Domingo: Op. Cit., pp. 26 y 247-250.

13 Acerca del estudio de este sistema, véase MÉNDEZ PLAZA, Santiago: Costumbres comunales de Aliste. Madrid, Real Academia de Ciencias Morales y Políticas, 1900. Edición reimpresa por Editorial Semuret (Zamora) y el Ayuntamiento de Riofrío de Aliste, 2002, prologada por Juan Ignacio Plaza Gutiérrez y Luis Alfonso Hortelano Mínguez.

14 PLAZA GUTIÉRREZ, Juan Ignacio: Aprovechamiento agrario y usos del suelo en la penillanura zamorana. La Tierra de Aliste. Salamanca, Universidad de Salamanca, 1989, pp. 15-16.

15 PLAZA GUTIÉRREZ, Juan Ignacio: Estructura del espacio geográfico y políticas territoriales en la Tierra de Aliste (Zamora). Salamanca, Junta de Castilla y León-Universidad de Salamanca, 1990, p. 294. 
simplemente, denunciando sus precarias condiciones de vida ${ }^{16}$. Poco antes, el Consejo Económico Sindical Provincial había señalado la existencia de 63 núcleos de población sin acceso por carretera en la provincia, buena parte de ellos en Aliste ${ }^{17}$.

En la actualidad, cuestiones básicas como la luz eléctrica, el agua potable, el alcantarillado y el teléfono están cubiertas en todo el territorio y ya no quedan núcleos sin carretera, pero aún así la accesibilidad es deficiente en algunas zonas. La principal vía de comunicación es la N-122, de Zaragoza a Portugal por Soria, Valladolid y Zamora, y que cruza transversalmente el sur de la comarca. Se encuentra en perfecto estado en cuanto a trazado, firme y anchura, no así la N-631, que discurre por el extremo nororiental del territorio. Pese a que comunica Zamora con el noroeste de la provincia y Galicia, y que su tráfico es de 3.201 vehículos diarios en Tábara ${ }^{18}$, es estrecha para ser una carretera nacional y su firme es irregular en algunos puntos.

De la red autonómica de Castilla y León, las principales vías en la zona son la ZA-324 y la ZA-912, de Ricobayo de Alba a la frontera portuguesa y de Alcañices a Villardeciervos, respectivamente. Son vías de poco tráfico ${ }^{19}$, pero su estado es bueno. Sin embargo, no ocurre lo mismo con la ZA-902 y la ZA321, que comunican Fonfría con Tábara y Bermillo de Sayago, respectivamente, y que pese a su interés comarcal son muy estrechas y tienen un firme muy malo. Es algo mejor -aunque tampoco buena- la situación de las principales carreteras de la Diputación de Zamora en la zona.

En cuanto al ferrocarril, la línea Zamora-Ourense cruza el noreste de la comarca, pero ningún tren de largo recorrido hace parada aquí, y sólo existe un servicio de media distancia por sentido, que realiza la ruta Puebla de Sanabria-Zamora-Valladolid y viceversa. El tren regional estaba llamado a desaparecer con los reajustes realizados por Renfe en junio de 2013, pero finalmente se ha mantenido.

\subsection{Vínculos con Portugal y patrimonio cultural}

Aliste limita con la región portuguesa de Trás-os-Montes, cuya capital, Bragança, dista unos 40 kilómetros de Alcañices y apenas 100 de Zamora. A uno

16 Ibid., pp. 198-200.

17 SEISDEDOS ROBLES, Juan: Estructura y perspectivas de desarrollo económico de la provincia de Zamora. Zamora, Consejo Económico Sindical Provincial, 1971, pp. 217-218.

18 Fuente: Mapa de Tráfico de la Red de Carreteras del Estado 2012. <http://www.fomento.es/ MFOM/LANG_CASTELLANO/DIRECCIONES_GENERALES/CARRETERAS/TRAFICO_VELOCIDADES/MAPAS/> [Fecha de consulta: 21 de agosto de 2013].

19 Fuente: Mapa de Tráfico de la Red Regional de Carreteras de Castilla y León en la provincia de Zamora 2012. < http://www.jcyl.es/web/jcyl/binarios/731/776/imd_zamora,1. pdf?blobheader=application $\% 2$ Fpdf\%3Bcharset $\% 3$ DUTF-8\&blobheadername $1=$ CacheControl\&blobheadername $2=$ Expires \&blobheadername $3=$ Site $\&$ blobheadervalue $1=$ no -store $\% 2$ Cno-cache $\% 2$ Cmust-revalidate \&blobheadervalue2 $=0 \&$ blobheadervalue $3=\mathrm{JCYL}$ Fomento\&blobnocache $=$ true $>$ [Fecha de consulta: 21 de agosto de 2013] . 
y otro lado de "la Raya", como se conoce popularmente a la frontera, existe plena continuidad en el aspecto físico y socioeconómico ${ }^{20}$. Ambas zonas son "lejanas y marginales en relación a los principales centros de decisión" en los respectivos países, lo que ha dado pie a que haya un notable grado de relación entre ellas, superior a los vínculos con otras áreas de España y Portugal, antes incluso de la apertura de fronteras en el ámbito de la Unión Europea en $1993^{21}$. Algunas de esas manifestaciones son elementos como "similares trajes típicos, un folclore con sones parecidos y una gastronomía a base de los mismos productos”, según Hortelano Mínguez ${ }^{22}$. La máxima expresión de estas afinidades son las diversas romerías transfronterizas que se celebran en la zona y las fiestas de invierno de raíz pagana conocidas como mascaradas. Estas celebraciones conforman un rasgo distintivo de esta comarca muy característico, que se mantiene desde tiempos ancestrales y que se ha convertido también en un recurso cultural de primer orden.

\section{2. 'La Opinión-El Correo de Zamora'}

\subsection{Orígenes y evolución del diario}

El diario La Opinión-El Correo de Zamora se publica con este nombre desde el 7 de febrero de 1993, como resultado de la integración de una cabecera histórica y muy venida a menos en otra de fundación muy reciente pero había logrado consolidarse rápidamente. La Opinión de Zamora salió a la calle el 27 de marzo de 1990 de la mano del grupo editorial Prensa Ibérica, que por entonces llevaba a cabo una política de expansión mediante la adquisición de periódicos ya existentes o la creación de rotativos nuevos ${ }^{23}$. En su primer editorial, $L a$ Opinión advertía del riesgo que corría la provincia de "quedarse ensimismada", por factores negativos como "no hallarse en alguno de los grandes ejes que el progreso va trazando en el país", con la salida hacia el oeste "cegada" por la frontera con Portugal y la "emigración endémica". Ante esta situación, los responsables del diario estimaban que "el destino de Zamora no es quedarse inmóvil y sin nada que contar salvo su historia" 24 .

Por su parte, El Correo de Zamora había sido fundado en 1897 y tuvo desde bien temprano un perfil conservador, asociado a las posiciones de la Iglesia y

20 PLAZA GUTIÉRREZ, Juan Ignacio, Aprovechamiento agrario y usos... Op. Cit., p. 25.

21 PLAZA GUTIÉRREZ, Juan Ignacio: "Localización y estructura territorial", en HORTELANO MÍNGUEZ, Luis Alfonso (coord.): Op. Cit., p. 28.

22 HORTELANO MÍNGUEZ, Luis Alfonso: "La Raya. El territorio fronterizo entre Castilla y León y Portugal, un paisaje cultural", en SEBASTIÁN, Chany: Mascaradas. Antruejos de Zamora y Trás-os-Montes. Alcañices, Federación Comarcal de Asociaciones Culturales de Aliste, Tábara y Alba, 2004, pp. 144-145.

23 Información corporativa de Editorial Prensa Ibérica en su página web, $<\underline{\text { http://www.epi.es }>\text {. }}$ [Fecha de consulta: 26 de julio de 2013].

24 Ibídem, p. 3. 
los sindicatos agrarios ${ }^{25}$. Tras la Guerra Civil española fue el Diario del Movimiento en la provincia de Zamora, pasando más tarde al organismo público Medios de Comunicación Social del Estado y, al disolverse éste en 1984, a manos privadas. La fuerte competencia que supuso la irrupción de La Opinión y una grave crisis empresarial provocaron una decadencia cada vez más acusada, hasta que la cabecera fue adquirida por una sociedad del grupo Prensa Ibérica el 30 de julio de 1992. Al día siguiente ya no se publicó el periódico ${ }^{26}$. Meses más tarde, el 7 de febrero de 1993, La Opinión pasaba a llamarse La OpiniónEl Correo de Zamora, integrando a buena parte de la plantilla del histórico diario absorbido.

Desde entonces, La Opinión-El Correo de Zamora se ha consolidado como medio de referencia en la prensa escrita provincial. Ha tenido competencia, pero nunca ha visto peligrar su liderazgo; según Miguel Ángel Mateos, tuvo la virtud de "irrumpir con fuerza" entre "una clientela que anhelaba cambios", al "quebrar monopolios y ensanchar la pluralidad"27. Desde mayo de 2013 la hegemonía es total, tras el cierre de la edición que el diario salmantino El Adelanto realizaba para la provincia de Zamora ${ }^{28}$. La Oficina de Justificación de la Difusión (OJD) cifra las ventas en 5.558 ejemplares diarios de media en $2012^{29}$, un dato bastante elevado teniendo cuenta la población de la provincia y la crisis estructural que sufre en la actualidad la prensa diaria.

La Opinión-El Correo de Zamora ha logrado convertirse en lo que estudiosos del ámbito de la comunicación como Xosé López García han definido como "espacios de proximidad" para sus lectores: el periódico no sólo se ciñe a un espacio territorial determinado, sino que se identifica plenamente con sus rasgos identitarios. De esta forma, los lectores pueden sentir que un medio determinado es su periódico, el que defiende los intereses de su zona ${ }^{30}$. En esta línea, el diario zamorano ha incidido de forma muy notable en los últimos años en los contenidos locales, tanto los referidos a la capital como al resto de la provincia; el máximo ejemplo de esto es la creación de una edición específica para Benavente y comarca.

25 Información corporativa de Editorial Prensa Ibérica.

26 La Opinión de Zamora (31-7-1992), p. 1.

27 Ibídem.

28 <http://www.fape.es/cierra-el-diario-el-adelanto-decano-de-la-prensa-de-salamanca_fape81882447.htm> [Fecha de consulta: 26 de julio de 2012].

29 Dato disponible en la web de la OJD, <www.introl.es $>$. [Fecha de consulta: 26 de julio de 2012].

30 LÓPEZ GARCÍA, Xosé: Desafíos de la comunicación local: guía práctica de la información en los ámbitos de proximidad. Sevilla, Comunicación Social Ediciones y Publicaciones, 2004, pp. 24-29. 


\subsection{La información de "Comarcas" en 'La Opinión-El Correo de Zamora'}

La información de ámbito local y comarcal ocupa habitualmente en torno a 9-10 páginas en La Opinión-El Correo de Zamora, si excluimos el espacio reservado a los temas de la capital. Estos contenidos se estructuran en tres secciones distintas: "Benavente", "Toro" y "Comarcas". Las dos primeras se corresponden, obviamente, con las principales localidades de la provincia tras la ciudad de Zamora, pero también recogen información de sus respectivos ámbitos comarcales. La sección de Benavente suele ocupar tres páginas, mientras que en el caso de Toro son dos.

La información de Comarcas se extiende por lo general a lo largo de cinco páginas, conformando un apartado claramente diferenciado. Creemos que esto es un signo del interés por estos contenidos. En este sentido, Celedonio Pérez, redactor jefe de La Opinión de Zamora y responsable de la sección, señala que "el periódico siempre ha apostado por los pueblos y por el campo, porque han sido elementos característicos de la provincia"31. Hay que tener en cuenta, añade, que se trata de un territorio "muy rural", ya que "prácticamente la mitad de la población" vive en municipios con menos de 2.000 habitantes. Por ello "se intenta equiparar" en el periódico su presencia a la de la capital. A juicio del redactor jefe, "se cubre bastante bien la provincia", bien a través de los corresponsales comarcales -en Benavente se cuenta incluso con una pequeña delegación- o de los redactores de la sección de Comarcas.

En Aliste, Tábara y Alba, la cobertura corre habitualmente a cuenta del corresponsal Sebastián Calvo, que firma sus artículos con el nombre de Chany Sebastián ${ }^{32}$. Vecino del pueblo alistano de Valer, comenzó a colaborar en 1988 con $\mathrm{El} \mathrm{Correo} \mathrm{de} \mathrm{forma} \mathrm{puntual,} \mathrm{pero} \mathrm{poco} \mathrm{a} \mathrm{poco} \mathrm{fue} \mathrm{consolidándose} \mathrm{como}$ corresponsal en estas comarcas, apoyándose en su exhaustivo conocimiento de la zona y de sus habitantes. Calvo asegura que, en estos momentos, su agenda supera los 700 teléfonos, pertenecientes a todo tipo de agentes sociales de Aliste, Tábara y Alba, hasta el punto de ser conocido por autoridades y vecinos de todos los pueblos de la zona ${ }^{33}$.

Es él quien habitualmente escoge los asuntos a tratar, con una especial atención a "reivindicar la comarca lo que se hace"; a su juicio, la publicación de artículos es una forma de "remover conciencias y hacer que se actúe", en casos como la construcción o reparación de infraestructuras, un asunto que "crea debate en los pueblos" y que influye en la calidad de vida de sus habitantes. Chany considera que La Opinión-El Correo de Zamora contribuye a "generar sentimiento comarcal", al exponer las necesidades y reivindicaciones de la

31 Entrevista con Celedonio Pérez. Zamora, 5 de abril de 2013.

32 Chany es una forma coloquial de referirse en la zona a las personas llamadas Sebastián, de la que se sirve el corresponsal para hacer un juego de palabras a la hora de firmar sus artículos.

33 Entrevista con Sebastián Calvo. Alcañices, 3 de abril de 2013. 
zona, así como sus manifestaciones culturales. A su juicio, la clave es "mostrar la cotidianeidad de la gente", ya que eso hace que los vecinos se sientan identificados con el diario. En 25 años de trabajo, el corresponsal se ha convertido en un referente del periodismo en la comarca, hasta el punto de que muchos se refieren simplemente a "Chany" para aludir a La Opinión-El Correo.

\section{LA PUESTA EN VALRO DE LOS RECURSOS TERRITORIALES}

La Opinión-El Correo de Zamora, aun siendo un agente externo al territorio, contribuye a impulsar el desarrollo endógeno de Aliste, Tábara y Alba, mediante la difusión y puesta en valor de recursos muy diversos, así como de sus necesidades y exigencias. Vázquez Barquero define el citado concepto desde el planteamiento de que todos los territorios cuentan con una serie de recursos, quelos cuales conforman un potencial de desarrollo ${ }^{34}$. Hace hincapié en aspectos como "un sistema sociocultural fuertemente vinculado al territorio" como base del "sistema productivo local" 35 , y destaca, en este sentido, la "fuerte relación que se establece entre empresa, cultura y territorio".

Apoyado en estos argumentos, Antonio Martínez Puche define el desarrollo local como un proceso encaminado al progreso "no sólo económico sino también social y cultural de un territorio determinado, emprendido y gestionado por entes administrativos y sociales locales o mancomunidades" ${ }^{\prime 36}$. En la puesta en marcha de estas estrategias destaca cuatro aspectos fundamentales: valorización de los recursos locales, interés colectivo, procesos de democratización local y partenariado, con un frecuente carácter "voluntarista". La mayoría de los estudios sobre desarrollo local resaltan la importancia de ceñir las políticas a un entorno territorial perfectamente definido. Miguel Ángel Troitiño señala que las economías locales guardan una "estrecha relación" con la "identidad" del territorio perfilada a lo largo del tiempo; por ello, sostiene que "las acciones de desarrollo también deben ser analizadas en términos de ordenación del territorio" ${ }^{37}$. Así, estima que para llevar a cabo un proyecto de este tipo hay que "vertebrar la sociedad" a su alrededor.

34 VÁZQUEZ BARQUERO, Antonio: "Desarrollo local y territorio", en PÉREZ RAMÍREZ, Bartolomé; CARRILLO BENITO, Emilio: Desarrollo local: manual de uso. Madrid, ESIC y Federación Andaluza de Municipios y Provincias, 2000, pp. 95-96.

35 Ibídem, p. 101.

36 MARTÍNEZ PUCHE, Antonio: "Desarrollo local y gestión del "crecimiento económico". Instrumentos para la superación de las desigualdades socioeconómicas de los territorios", en MARTÍNEZ PUCHE, Antonio; PÉREZ PÉREZ, David; SANCHO CARBONELL, Isabel: Eines per al desenvolupament local / Herramientas para el desarrollo local. Cocentaina, CEDER Aitana y Universidad de Alicante, 2000, p. 29.

37 TROITIÑNO VINUESA, Miguel Ángel: "El territorio y la revalorización de los recursos endógenos en el desarrollo local”, en MARTÍNEZ PUCHE, Antonio; PÉREZ PÉREZ, David; SANCHO CARBONELL, Isabel: Herramientas... Op. Cit., pp. 106-107. 
En la misma línea, José Manuel del Barrio defiende la comarcalización en las políticas de desarrollo local y rural, ya que, en su opinión, esta división territorial es una "opción ante la crisis de las entidades municipales" y "las dificultades que se derivan del minifundismo municipal". Defiende, entre otros aspectos, que una adecuada comarcalización contribuye a paliar desequilibrios territoriales, al tiempo que favorece la descentralización política y acerca con ello la administración a los ciudadanos ${ }^{38}$. El mismo concepto propugna Andrés Precedo, para quien la fórmula comarcal incide en el refuerzo de la identidad territorial, ya que la comarca se corresponde con un entorno "enraizado en la tradición" 39 . Asegura que este modelo también contribuye a "despertar iniciativas, generar proyectos, promover pequeñas empresas, abrirse a los mercados..." y, en definitiva, a "la creación de tejido social".

\section{El reflejo del desarrollo local en 'La Opinión-El Correo De Zamora'}

Las distintas políticas de desarrollo local que se llevan a cabo en el ámbito geográfico de Aliste, Tábara y Alba tienen un reflejo casi diario en La Opinión-El Correo de Zamora. La promoción territorial se hace a menudo de forma implícita, en noticias que versan sobre la dotación de servicios e infraestructuras, la situación de los sectores económicos presentes en la zona, la cultura y las tradiciones locales, la participación ciudadana y la identidad territorial, entre otros aspectos. Hemos analizado distintas áreas temáticas en las que estimamos que La Opinión-El Correo de Zamora realiza su contribución al desarrollo local de Aliste, Tábara y Alba. Son las siguientes: cultura, servicios e infraestructuras, desarrollo económico, población y sociedad, y la presencia del lobo ibérico en la zona. A estos apartados sumamos un aspecto que subyace en muchos textos: la relación con los territorios vecinos de Portugal.

\subsection{Cultura-fiestas: entre la etnografía y el lado más lúdico}

La presencia de artículos sobre cultura y fiestas es constante a lo largo del año en La Opinión-El Correo de Zamora, ya que prácticamente en cualquier momento se celebra algo susceptible de aparecer en el periódico, o se produce algún acontecimiento relacionado con ello. Se reflejan tanto las festividades más lúdicas como aquellas que llevan implícito un elevado componente etnográfico, bien porque son representaciones de gran singularidad -como las mascaradas de invierno que tienen lugar en varias poblaciones de la comarca- o porque en ellas se dan cita un gran número de personas, caso de las romerías transfronterizas que se celebran al cabo del año. Las fiestas patronales de los distintos

38 DEL BARRIO ALISTE, José Manuel: Op. Cit., p. 316.

39 PRECEDO LEDO, Andrés: "La comarcalización en España: evolución reciente y nuevas perspectivas", en Territorio y desarrollo local, número 9, pp. 23-24. Zaragoza, Departamento de Política Territorial e Interior del Gobierno de Aragón, 2007. 
municipios -que se celebran casi sin excepción en julio y agosto- tienen también un gran protagonismo en el periódico.

Las mascaradas son, sin duda, las grandes protagonistas en este apartado. Ya en el primer número del año, el del 2 de enero ${ }^{40}$, encontramos una referencia a las fiestas tradicionales de Aliste, con la crónica de las mascaradas celebradas el día de Año Nuevo en la comarca: los Carochos de Riofrío de Aliste y el Cencerrón de Abejera. Ambas se llevan a la portada, junto con el Zangarrón de Montamarta - población que queda fuera de nuestro ámbito de estudio-, conformando una composición de tres fotografías con un titular común ${ }^{41}$. En el interior del periódico, cada una de estas fiestas tiene su propia crónica a página completa, con varias fotografías, una descripción de la fiesta, la enumeración de los personajes, la narración de su desarrollo, algunos detalles sobre sus vicisitudes históricas ${ }^{42} \ldots$ El corresponsal del periódico en la zona, Chany Sebastián, apoya esta crónica y otra al día siguiente con sendos artículos de opinión, en los que aporta información complementaria $-\mathrm{y}$, por ende, un valor añadido- de estas fiestas, como el porqué del nombre de alguno de los personajes que intervienen, e incide en que estos actos "representan un legado social, cultural y etnográfico de infinito valor que ha sobrevivido desde la noche de los tiempos hasta nuestros días gracias a la voluntad de las gentes de nuestros pueblos", tanto en Aliste como en las vecinas tierras portuguesas de Trás-os-Montes.

El propio periódico dedica a estas fiestas un editorial el 8 de enero, con el título "Las mascaradas de invierno, un patrimonio que Zamora debe proteger". El en él se insiste en que ha sido precisamente el hecho de que la provincia haya permanecido apartada de los grandes focos de desarrollo lo que ha permitido conservar estas manifestaciones culturales, que califica de "retazos de una cultura agraria y ancestral que agoniza en el conjunto del país y que aquí tiene todavía cierto tono vital" ${ }^{\text {‘3 }}$. También se apela a aspectos como la fijación de un calendario oficial de mascaradas -reforzando así su mantenimiento y evitando solapamientos en los horarios- o la incorporación de mujeres a las mismas, ya que tradicionalmente sólo los hombres han intervenido en ellas.

Precisamente, a lo largo de 2012 se dio una situación en la que se puso de manifiesto esta disyuntiva entre dar paso a la participación de mujeres en las mascaradas o tener que suspenderlas. La celebración del Tafarrón, en Pozuelo de Tábara, peligraba por falta de varones jóvenes, por lo que se hizo una consulta a los vecinos del pueblo para ver si aceptaban la participación de una chica. El posicionamiento del periódico fue claramente a favor; cuando, final-

40 Como norma general, la prensa diaria no se publica los días 1 de enero y 25 de diciembre, así como el Viernes Santo. La Opinión-El Correo de Zamora es fiel a esta regla.

41 La Opinión-El Correo de Zamora (2-1-2012), p. 1.

42 La Opinión-El Correo de Zamora (2-1-2012), pp. 27-28; y La Opinión-El Correo de Zamora (3-1-2013), p. 22.

43 La Opinión-El Correo de Zamora (8-1-2012), p. 19. 
mente, la joven hizo historia al ser la primera en tomar parte en el Tafarrón, el tema se llevó a la portada y se le dedicó una página prácticamente completa. También el redactor jefe del periódico, Celedonio Pérez, dedicó una tribuna a este asunto, afirmando que la apertura de las mascaradas a las mujeres "es una necesidad y, sobre todo, es de justicia" ${ }^{44}$. Consideramos que el periódico hizo presión para cambiar una costumbre social anacrónica en un momento muy oportuno. Asimismo, se contribuyó a modernizar la sociedad rural al tiempo que se potenciaba una manifestación tradicional genuina.

Por otra parte, el periódico también refleja con mucha frecuencia otra muestra de la cultura tradicional alistana significativa como el folclore. Se difunden las iniciativas que surgen en este terreno, como un nuevo festival en Carbajales de Alba, haciendo especial hincapié siempre que detrás hay personas jóvenes ${ }^{45}$. La exaltación etnográfica se extiende a a aspectos como las costumbres de antaño hoy prácticamente perdidas; ejemplos de ello son una demostración de oficios tradicionales del campo en Vegalatrave ${ }^{46}$, o una fiesta de la matanza del cerdo en Tábara ${ }^{47}$, entre otras.

Asimismo, se presta mucha atención a fiestas tradicionales de carácter fundamentalmente religioso que tienen lugar en la comarca; entre las más destacadas está la procesión del Viernes Santo de Bercianos de Aliste, declarada de Interés Turístico Regional y dotada de una vistosidad muy llamativa ${ }^{48}$. La celebración en sí se cuenta en un suplemento especial de Semana Santa, junto con el resto de actos característicos de esos días en toda la provincia de Zamora, pero además, durante el resto del año el periódico refleja cualquier noticia relacionada con esta festividad ${ }^{49}$. Otras fiestas religiosas importantes en la comarca reciben también un tratamiento profuso, pero más concentrado en el tiempo -en el mismo momento de su celebración y en los días previos-, como las romerías de Moveros, Villarino de Manzanas, San Martín del Pedroso y Alcañices, que sobresalen porque congregan a fieles de ambos lados de la frontera hispano-lusa, algo que se destaca mucho como símbolo de hermanamiento ${ }^{50}$.

44 La Opinión-El Correo de Zamora (24-12-2012), pp. 1, 20 y 31.

45 La Opinión-El Correo de Zamora (26-7-2012), p. 22. Entrevista a Alfredo Domínguez Prada, promotor del I Festival de Folclore Villa de Carbajales.

46 La Opinión-El Correo de Zamora (12-8-2012), p. 20.

47 La Opinión-El Correo de Zamora (2-3-2012), p. 24.

48 En esta procesión, algunos de los hombres participantes visten una túnica que les habrá de servir de mortaja llegado el día, mientras que otros llevan puesta la capa parda característica de la zona. La celebración tiene su propio espacio web en la página oficial de Turismo de Castilla y León: <http://www.turismocastillayleon.com/cm/turcyl/tkContent?pgseed=1135729507898\&i dContent=9965\&locale=es ES\&textOnly=false $>$ [Fecha de consulta: 28 de agosto de 2013].

49 La Opinión-El Correo de Zamora (16-4-2012), p. 38; La Opinión-El Correo de Zamora (87-2012), p. 24; y La Opinión-El Correo de Zamora (11-3-2012), p. 24.

50 La Opinión-El Correo de Zamora (30-4-2012), p. 39; La Opinión-El Correo de Zamora (14-5-2012), p. 41; La Opinión-El Correo de Zamora (28-5-2012), p. 34; y La Opinión-El Correo de Zamora (3-7-2012), pp. 22-23. 
Las fiestas populares alistanas son otro elemento de gran interés para $\mathrm{La}$ Opinión-El Correo de Zamora. Las celebraciones patronales de todas y cada una de las localidades, incluso las más pequeñas, tienen su oportuno reflejo en el periódico. El verano es la época más profusa en estos temas, donde llegan a coincidir en el tiempo las fiestas de varios pueblos ${ }^{51}$. Las crónicas de fiestas pueden abordar actos de todo tipo; así, podemos leer desde la procesión de San Pedro de Gallegos del Río ${ }^{52}$ hasta la parrillada popular de Ricobayo de Alba ${ }^{53}$, pasando por los espantes -suelta de toros en el campo para ser llevados hasta el casco urbano- de Carbajales de Alba ${ }^{54}$.

Por último, algunas de las festividades guardan relación con aspectos de la identidad colectiva, ya que en ellas se suele reforzar el sentimiento de pertenencia a la tierra. La más destacada y explícita es el Día de la Comarca de Aliste, Tábara y Alba. Organizado por la Federación de Asociaciones Culturales de Aliste, Tábara y Alba, se celebra desde 1989 con una periodicidad anual prácticamente ininterrumpida -sólo dejó de celebrarse en 1994-, cada vez en una localidad distinta. En él se hace una muestra de folclore, artesanía y gastronomía comarcales, a la vez que se reivindica la personalidad colectiva de estas tierras. En 2012 tuvo lugar en Trabazos, y el periódico le prestó un seguimiento exhaustivo. Primero, con la elección del citado pueblo como sede ${ }^{55}$; y después, con una entrevista al alcalde ${ }^{56}$ y la publicación de un especial de seis páginas ${ }^{57}$. Con ello, se difundió al resto de la provincia los atractivos turísticos y el potencial económico de la zona, al tiempo que reforzaba la cohesión interna comarcal.

4.2. Servicios-infraestructuras: el periódico como altavoz de las reivindicaciones

La Opinión-El Correo de Zamora presta una gran atención a lo que acontece en los pueblos de la provincia en cuanto a dotación de servicios y estado de las infraestructuras. Las temáticas son variadas, pero con un denominador común: la demanda de una mejora en la calidad de vida de los vecinos. Con frecuencia, los artículos inciden en la escasa dimensión demográfica de los pueblos afectados, pero recalcando siempre el derecho de la población a que sus demandas sean antendidas.

51 La Opinión-El Correo de Zamora (15-8-2012), pp. 19-20

52 La Opinión-El Correo de Zamora (30-6-2012), p. 22.

53 La Opinión-El Correo de Zamora (11-8-2012), p. 24.

54 La Opinión-El Correo de Zamora (9-9-2012), p. 22.

55 La Opinión-El Correo de Zamora (5-3-2012), p. 44.

56 La Opinión-El Correo de Zamora (13-7-2012), p. 20. El titular de la entrevista habla por sí solo de la personalidad comarcal: "La zona tiene como principal valor el esfuerzo para sobrevivir en una tierra dura".

57 La Opinión-El Correo de Zamora (14-7-2013), pp. 24-29. 


\subsubsection{Las mejoras en la red viaria}

Las infraestructuras son un tema frecuente en el periódico, ya que se suelen recoger las denuncias por el mal estado en el que se pueda encontrar alguna vía o las obras que se desarrollen en un momento dado. Un ejemplo de lo primero lo tenemos en el artículo donde se pone de manifiesto el deficiente acceso a Villarino tras la Sierra, en el que se destaca que los vecinos de este pueblo optan por llegar a él a través de Portugal, ante el deterioro de la vía que enlaza directamente con la N-12258. La noticia, además, viene apoyada por uno de los característicos artículos de opinión del corresponal, titulado "La soledad del abandono" y con el subtítulo "Un pueblo que siempre ha estado al final de todo". Cabe señalar que esta demanda en concreto tuvo éxito: cinco meses después, la Diputación de Zamora inició la mejora de la carretera de acceso a Villarino ${ }^{59}$.

Las dos carreteras nacionales que pasan por la comarca también son objeto de reivindicación, especialmente la $\mathrm{N}-631$, por hallarse en un estado regular. El periódico recoge las demandas del Ayuntamiento de Tábara para que el Ministerio de Fomento acondicione la travesía, y cómo, ante la callada por respuesta, el consistorio decide hacerlo con sus propios fondos, con tal de mejorar el tránsito peatonal ${ }^{60}$. Quizá en este caso también el Ministerio acabó dándose por aludido, porque en diciembre de 2012 al fin se anunció la construcción de aceras en la travesía, entre otras obras ${ }^{61}$.

En los últimos 20 años se han abierto varias carreteras locales que comunican los pueblos alistanos con Portugal. El periódico recoge todos los avances en este sentido, dándoles siempre el enfoque de que ponen en contacto territorios vecinos con muchas afinidades. Así se resalta al hablar de la apertura del paso fronterizo de Riomanzanas ${ }^{62}$, y también ante el inicio de las obras de otra nueva carretera desde Villarino de Manzanas, pueblo muy cercano al anterior y perteneciente al mismo municipio, Figueruela de Arriba ${ }^{63}$; esta vía se ha abierto también al tráfico en el verano de 2013.

4.2.2. Transporte público: la lucha por mantener servicios en un territorio despoblado

En una zona con tan poca población como Aliste, Tábara y Alba, los servicios de transporte público son escasos, pero se da la paradoja de que para los

58 La Opinión-El Correo de Zamora (27-1-2012), p. 23.

59 La Opinión-El Correo de Zamora (12-6-2012), p. 23.

60 La Opinión-El Correo de Zamora (19-7-2012), p. 22; La Opinión-El Correo de Zamora (98-2012), p. 22; y La Opinión-El Correo de Zamora (29-10-2012), p. 42.

61 La Opinión-El Correo de Zamora (26-12-2012), p. 21.

62 La Opinión-El Correo de Zamora (12-5-2012), p. 22.

63 La Opinión-El Correo de Zamora (24-8-2012), p. 26. 
usuarios es esencial su existencia. Por lo general son personas de edad muy avanzada que ya no se encuentran en condiciones de desplazarse en vehículo privado, o que, incluso, nunca han dispuesto de él. La disyuntiva entre la falta de rentabilidad económica y la necesidad social se ha mostrado con fuerza en los últimos dos años, en medio de la política de recortes emprendida desde las administraciones públicas. En este sentido, el posicionamiento de La OpiniónEl Correo de Zamora ha sido claro, siempre a favor de una asistencia a los vecinos del medio rural, por encima de consideraciones puramente mercantilistas. Por ejemplo, cuando en octubre de 2012 se anunció la eliminación de un autobús vespertino entre Zamora y San Cristóbal de Aliste, pasando por más de 20 localidades de la comarca. De inmediato, el periódico se hizo eco del acuerdo alcanzado por todos los alcaldes afectados -de distintos partidos políticos- para el mantenimiento del servicio; uno de los artículos se ilustraba con una foto del microbús que cubría el trayecto, en la que podía verse avanzada edad de los usuarios ${ }^{64}$.

La misma postura se dio ante el anuncio de que la comarca se iba a quedar sin servicio ferroviario alguno. En abril de 2013 se conoció que el Ministerio de Fomento pretendía eliminar el tren regional entre Zamora y Puebla de Sanabria, dentro de la supresión de servicios de media distancia altamente deficitarios ${ }^{65}$. Unos días después, La Opinión-El Correo de Zamora ya defendió la continuidad del servicio en un editorial ${ }^{66}$, y en las semanas siguientes también se publicaron numerosos artículos de opinión en la misma línea ${ }^{67}$. Asimismo, se dio una amplia cobertura a todas las protestas que se realizaron, como el bloqueo de las vías de la estación de Zamora por parte de 300 personas llegadas desde Aliste y Sanabria -muchas de ellas de edad avanzada-, impidiendo la salida del tren Alvia Madrid-A Coruña ${ }^{68}$; o la celebración de una manifestación en la capital, con la asistencia también de numerosos vecinos de los pueblos alistanos y sanabreses afectados por el recorte ${ }^{69}$. En todos estos artículos se hablaba insistentemente de la "rentabilidad social" del servicio existente y se daba voz a los damnificados por la decisión de Fomento, como al alcalde pedáneo de Cabañas de Aliste, quien recalcaba que el tren era el único medio de transporte público en el pueblo.

Es demasiado aventurado aseverar que el Ministerio cedió ante las presiones de los habitantes de Aliste y Sanabria, reflejadas en La Opinión-El Correo

64 La Opinión-El Correo de Zamora (4-10-2012), p. 20; y La Opinión-El Correo de Zamora (10-10-2012), p. 22.

65 La Opinión-El Correo de Zamora (6-4-2013), p. 7.

66 La Opinión-El Correo de Zamora (14-4-2013), p. 19.

67 La Opinión-El Correo de Zamora (17-5-2013), p. 19; La Opinión-El Correo de Zamora (18-5-2013), p. 41; La Opinión-El Correo de Zamora (20-5-2013), p. 18; y La Opinión-El Correo de Zamora (2-6-2013), p. 18.

68 La Opinión-El Correo de Zamora (11-5-2013), pp. 1-2 y 48.

69 La Opinión-El Correo de Zamora (31-5-2013), pp. 1-3. 
de Zamora, pero lo cierto es que la supresión del servicio de media distancia a Puebla de Sanabria, anunciada inicialmente para el 1 de junio, se paralizó la misma tarde del día anterior. En principio se dijo que se retrasaba hasta el 23 de ese mes, alegando que quería establecerse un plan de transporte alternativo ${ }^{70}$. Sin embargo, llegada esa otra fecha, y casi con la misma premura, se anunció la continuidad definitiva del tren regional, con los mismos horarios y paradas. La versión oficial fue la inviabilidad de una hipotética alternativa por carretera ${ }^{71}$; no obstante, consideramos que en esta decisión final influyó el rechazo generalizado a la intención de suspender el servicio, y que, en este sentido, el periódico tuvo un papel fundamental como altavoz de las demandas ciudadanas.

\subsubsection{La defensa de la calidad asistencial}

La situación de los servicios en general en la comarca de Aliste es otra constante en La Opinión-El Correo de Zamora. El periódico refleja todos los cambios que se van produciendo, así como todas las protestas ciudadanas que se llevan a cabo si esas modificaciones son a peor. El ejemplo más destacado es el de la sanidad, donde los ajustes en las prestaciones llevados a cabo por la Junta de Castilla y León generaron malestar en algunos pueblos. El cierre de las urgencias nocturnas en el centro de salud de Muelas del Pan acarreó el rechazo público de los ayuntamientos afectados y la convocatoria de diversas protestas, puntualmente difundidas a través del diario.

Así, poco después de que los alcaldes de Almaraz de Duero -comarca de Tierra del Pan- y el propio Muelas se mostraran contrarios al recorte, un grupo de vecinos comenzó a concentrarse ante el centro de salud, para pasar poco después a encerrarse por las noches en las instalaciones ${ }^{72}$. La protesta se llevó también a las calles de Zamora en varias ocasiones, y más tarde a Valladolid, con la presencia también de afectados de otros puntos de Castilla y León ${ }^{73}$. Meses más tarde, en agosto de 2013, la Junta anunció la reapertura de todas las urgencias sanitarias cerradas un año antes, alegando que había logrado ahorrar un millón de euros con esta medida ${ }^{74}$. Al igual que en el caso del tren, creemos aventurado decir que la administración autonómica cedió ante las presiones ciudadanas, pero podemos aseverar que La Opinión-El Correo de Zamora hizo de canal para que el malestar de los afectados llegara directamente a las autoridades.

70 La Opinión-El Correo de Zamora (1-6-2013), pp. 1-3.

71 La Opinión-El Correo de Zamora (21-6-2013), pp. 1-2.

72 La Opinión-El Correo de Zamora (15-9-2012), p. 20; La Opinión-El Correo de Zamora (25-9-2012), p. 23; La Opinión-El Correo de Zamora (15-10-2012), p. 41; y La Opinión-El Correo de Zamora (19-10-2012), p. 20.

73 La Opinión-El Correo de Zamora (25-11-2012), p. 25; La Opinión-El Correo de Zamora (23-12-2012), p. 20; y La Opinión-El Correo de Zamora (30-12-2012), p. 22.

74 La Opinión-El Correo de Zamora (9-8-2013), p. 26. 
Hay que destacar que servicios que no se tienen habitualmente por públicos y que en otro lugar resultarían mundanos aquí cobran gran excepcionalidad, un enorme sentido de necesidad social o ambas cosas a la vez. Si se tiene eso en cuenta, se podrá comprender por qué un pueblo de apenas 100 habitantes como Losacio tiene un bar de propiedad municipal, y qué drama puede suponer que los adjudicatarios dejen la concesión y no haya nadie que quiera seguir con el establecimiento.

El periódico concedió a este tema tal relevancia que ocupó dos páginas ${ }^{75}$. $\mathrm{El}$ asunto se recogía con la mayor formalidad posible, entrevistando al alcalde y a la juez de paz del pueblo. Además, se le dio la foto principal de la portada, con el primer edil apoyado sobre la solitaria barra y un titular que casi parecía un anuncio: "Losacio alquila su único bar por 100 euros al mes". Creemos que, de esta forma, se quería llamar la atención acerca del problema que para los vecinos podía ser el cierre del establecimiento y tratar de evitarlo, contribuyendo a la búsqueda de un nuevo arrendatario. La situación de Losacio no se planteaba como un caso único, sino como un ejemplo de las consecuencias de la despoblación del medio rural, donde un bar es más un centro social -puede que la única forma de socialización posible- que un negocio.

Es probable que desde el periódico consideraran que esta cobertura informativa podría hacer que alguien reaccionara y se ofreciera a tomar las riendas del bar. Y, de hecho, así fue en muy poco tiempo: sólo una semana después, una familia de Carbajales de Alba cerraba un acuerdo con el Ayuntamiento de Losacio para hacerse cargo del establecimiento durante un año ${ }^{76}$. Estimamos que éste es un ejemplo muy destacado de cómo un medio de comunicación, en este caso La Opinión-El Correo de Zamora, puede contribuir al desarrollo local en un municipio muy pequeño.

\subsection{Desarrollo económico: cualquier iniciativa es buena}

El panorama económico de Aliste, Tábara y Alba y las posibles alternativas de desarrollo son también un tema habitual en La Opinión-El Correo de Zamora. En una zona tan poco poblada e históricamente tan atrasada, cualquier opción de futuro que se plantee puede ser a priori buena, por lo que merece ser tenida en cuenta. Además, el territorio presenta un potencial interesante en aspectos como la ganadería o el turismo apoyado en los recursos naturales o patrimoniales.

\subsubsection{El potencial ganadero}

La ganadería es uno de los principales recursos económicos de Aliste y, en consecuencia, una de las actividades que más se aborda en La Opinión-El Correo

75 La Opinión-El Correo de Zamora (22-11-2012), pp. 1 y 22-23.

76 La Opinión-El Correo de Zamora (29-11-2012), p. 22. 
de Zamora. La calidad de la carne de ternera de la zona ha despuntado en los últimos años, tras la creación de una Marca de Garantía propia, propiciando unas perspectivas relativamente optimistas. Por ello, no debe extrañar que el sector vacuno tenga una presencia habitual en el periódico. Las características de los animales se tratan también con frecuencia, tanto desde el punto de vista de sus cualidades y de la demanda existente desde otras zonas de España ${ }^{77}$ como del de las tradiciones vinculadas a este ganado, caso por ejemplo de la trashumancia ${ }^{78}$.

Son habituales los artículos donde ganaderos de la comarca expresan su preocupación por mantener esas razas, tanto de vacuno como de ovino y de $\operatorname{asnos}^{79}$, por su potencial desde un punto de vista agroalimentario como por la difusión del territorio que llevan a cabo estos animales, al asociarse su existencia a un medio muy concreto. Además, el periódico también insiste en la necesidad de potenciar estos valores como motor económico de la provincia, incluso con editoriales ${ }^{80}$.

$\mathrm{El}$ asno de raza zamorano-leonesa tiene una presencia especial en $\mathrm{LaOPi}$ nión-El Correo de Zamora. Estos animales, de los que apenas existen un millar de ejemplares, son en buena medida un símbolo de estas tierras. Su presencia es casi exclusiva de aquí y, además, todavía se utilizan en las tareas del campo -probablemente no sería así sin la exagerada parcelación del terreno-, por lo que es bastante fácil verlos si se visita la zona. Villalcampo es el municipio de la comarca con una mayor concentración de asnos, lo que ha llevado a su Ayuntamietno a promover la puesta en valor de esta profusión animal como un rasgo identitario. Se ha creado un centro de interpretación sobre esta raza, el Aula del Asno Zamorano-Leonés, donde se muestran animales cedidos por los vecinos $^{81}$. El periódico va dando cuenta de la actividad de estas instalaciones, así como de otras actividades organizadas en Villalcampo en torno a esta raza; también se destaca en más de una ocasión que éste es el pueblo con una mayor presencia de este animal ${ }^{82}$.

\subsubsection{El recurso económico de setas y castañas}

La comarca de Aliste es una de las principales zonas micológicas de la provincia de Zamora, de forma que la recolección de setas es habitual, especialmente en la temporada otoñal. Además, han surgido empresas dedicadas a la transformación y comercialización de los hongos, algunas con una actividad bastante

77 La Opinión-El Correo de Zamora (12-11-2012), p. 40.

78 La Opinión-El Correo de Zamora (7-12-2012), p. 21.

79 La Opinión-El Correo de Zamora (21-5-2012), p. 18.

80 La Opinión-El Correo de Zamora (20-5-2012), p. 19.

81 La Opinión-El Correo de Zamora (23-10-2011), p. 25.

82 La Opinión-El Correo de Zamora (23-11-2012), p. 24. 
notable. Así, la micología se ha convertido en un reclamo turístico y un filón económico para varios municipios alistanos, del cual se va dando cumplida nota en el periódico.

El cobro de una tasa por coger setas a vecinos y foráneos es una de las principales vías de rentabilización de este recurso desde los municipios. Algunos lo hacen desde el proyecto autonómico Myasrc, que abarca todas las áreas productoras de Castilla y León ${ }^{83}$, aunque otros, como Mahide, han preferido desvincularse y gestionar directamente su potencial ${ }^{84}$. El valor de la comarca en este campo se cita de una forma muy habitual en el periódico, con noticias como la declaración en la zona de ocho Municipios Micológicos ${ }^{85}$ o el empadronamiento de ciudadanos portugueses en Aliste para así poder acogerse a las tasas de recolección más económicas ${ }^{86}$. Los temas más frecuentes, no obstante, son los relacionados con el resultado de la campaña y los precios de venta; los augurios que ofrece la situación meteorológica y los vaivenes en los costes en los mercados aparecen casi todas las semanas a lo largo de todo el otoño ${ }^{87}$.

Al mismo tiempo que las setas se promociona otro recurso natural con un claro potencial económico: las castañas. Este producto es también protagonista de artículos, como la cobertura de la Fiesta de la Castaña en Sejas de Aliste ${ }^{88}$. Asimismo, se informa puntualmente de las perspectivas de la campaña y los precios del producto ${ }^{89}$. De todas estas páginas se pone de manifiesto que las castañas, al igual que las setas, se identifican con el territorio y pueden atraer visitantes, al mismo tiempo que productores, recolectores y comercializadores pueden sacarle un rendimiento. La Opinión-El Correo de Zamora vuelve a ser clave en la difusión de estos valores.

\subsubsection{Las actividades turísticas}

Aliste, Tábara y Alba tiene diversos atractivos de tipo patrimonial, natural y cultural, de los que el periódico lleva también a cabo su particular campaña de difusión. En más de una ocasión aparecen entrevistas a cocineros de la zona, cuyos titulares y destacados dejan ver que, además de la rica gastronomía autóctona, hay más motivos para visitar el lugar. Un ejemplo: Agustín de Dios,

$83<$ <ww.myasrc.es> [Fecha de consulta: 2 de septiembre de 2013].

84 "Mahide se desvincula del proyecto regional micológico Myasrc", en La Opinión-El Correo de Zamora (6-10-2012), p. 22.

85 La Opinión-El Correo de Zamora (25-8-2012), 26.

86 La Opinión-El Correo de Zamora (21-10-2012), p. 22.

87 Ejemplos de esto: La Opinión-El Correo de Zamora (26-9-2012), p. 21; La Opinión-El Correo de Zamora (1-10-2012), p. 18; La Opinión-El Correo de Zamora (20-10-2012), p. 24; La Opinión-El Correo de Zamora (25-10-2012), p. 22; y La Opinión-El Correo de Zamora (7-11-2012), p. 24.

88 La Opinión-El Correo de Zamora (11-11-2012), p. 26.

89 La Opinión-El Correo de Zamora (27-10-2012), p. 24. 
cocinero y restaurador de Tábara, reivindica entre otros aspectos que "el lobo y la berrea del ciervo son ya un gran atractivo turístico"90. No es el único empresario del sector en la zona con una presencia así en el diario.

La apertura y el estado de conservación de los monumentos más importantes de la comarca también se aborda de manera oportuna, como el inicio de los horarios de verano de la Iglesia de Santa María de Tábara o el Convento de San Francisco de Alcañices, quizá los lugares más significativos de estas localidades ${ }^{91}$. Asimismo, se recogen reivindicaciones como la de la creación de un plan turístico específico para la Sierra de la Culebra ${ }^{92}$. Sin embargo, el sociólogo José Manuel del Barrio reflexiona en una columna de opinión acerca de lo poco que se conocen la mayoría de los atractivos de la provincia, y de cómo muchos pueblos sólo reciben visitantes en verano, cuando acuden a ellos los emigrantes, sus descendientes y amigos suyos. A su juicio, "algo falla en la tarea de difusión de nuestros recursos" ${ }^{93}$. En general, los artículos que abordan el tema van casi siempre en esa misma línea: hay un sinfín de atractivos, pero necesitan todavía de un gran impulso para su consolidación. En este sentido, creemos que el periódico hace aquí una función que desde otros frentes está incompleta.

\subsubsection{Las salidas agrarias}

La agricultura tiene en la comarca un peso específico menor que el de la ganadería, pero tiene cierta representatividad en ciertas zonas de regadío. El periódico es testigo de la modernización del anquilosado campo de Aliste con las acciones de concentración parcelaria. En el periodo estudiado se aprobaron dos medidas de este tipo, una conjunta en las localidades de Cerezal de Aliste y Villaflor, y la otra en Abejera. En el primer caso se destaca que 375 propietarios se repartirán unas 6.600 fincas tras la concentración ${ }^{94}$, mientras que en el segundo se destaca que los 14.480 minifundios existentes se reducirán a tan sólo 600 parcelas $^{95}$.

Otra temática de tipo agrario que nos encontramos es la introducción de nuevos cultivos en la comarca. En este sentido, vemos cómo una empresa norteamericana inicia en la localidad de Valer un cultivo experimental de frambuesas, y que unos meses después se lleva a cabo una jornada sobre este proyecto, considerando que esos frutos pueden ser "una fuente de riqueza sin explotar" 96.

90 La Opinión-El Correo de Zamora (7-3-2012), p. 24.

91 La Opinión-El Correo de Zamora (3-6-2012), p. 30; y La Opinión-El Correo de Zamora (9-6-2012), p. 23.

92 La Opinión-El Correo de Zamora (2-10-2012), p. 20.

93 La Opinión-El Correo de Zamora (19-8-2012), 16.

94 La Opinión-El Correo de Zamora (24-5-2012), p. 24.

95 La Opinión-El Correo de Zamora (9-10-2012), p. 22.

96 La Opinión-El Correo de Zamora (11-6-2012), p. 37; y La Opinión-El Correo de Zamora (28-9-2012), p. 23. 
También se cubre el inicio de cultivos de remolacha en Pozuelo de Tábara y Santa Eulalia de Tábara. El balance es además positivo, lo que hace guardar alguna esperanza de que pueda convertirse a medio plazo en una alternativa para algunas personas, aunque con el escepticismo de saber que en otras zonas de Castilla y León se está abandonando este mismo cultivo ${ }^{97}$.

\subsection{Población-sociedad-educación: alerta ante el vacío demográfico}

Los temas demográficos también tienen relevancia en La Opinión-El Correo de Zamora, ante la grave situación de despoblación y envejecimiento que padecen Aliste y toda la provincia. Ante un panorama tan poco alentador, cualquier noticia tiene máximo alcance, tanto si es positiva como negativa.

\subsubsection{La despoblación y sus consecuencias}

El despoblamiento es un tema visiblemente preocupante, no sólo por la escasez de habitantes en sí, sino porque la avanzada edad de muchos de ellos no invitan a pensar que la tendencia vaya a cambiar ni siquiera a largo plazo. Por ello, su reflejo en La Opinión-El Correo de Zamora va mucho más allá de la mera exposición de los datos: hay un análisis pormenorizado del tema, con la frecuente publicación de reportajes y de artículos de opinión al respecto. En los primeros se hace hincapié en aspectos como el elevado grado de masculinización de la población en toda la comarca, y en cómo eso frena la formación de familias ${ }^{98}$. Relacionado con la falta de gente, especialmente de niños, está el hecho de que en muchos pueblos no se celebren carnavales porque no hay quien se disfrace ${ }^{99}$, o que algunas romerías también ven peligrar su continuidad por la falta de personas jóvenes que carguen con las imágenes ${ }^{100}$.

El envejecimiento tiene también otra lectura: la longevidad. En la provincia de Zamora residen 3.525 personas con más de 90 años, de las cuales 118 -un $76 \%$ de ellas mujeres- llegan a superar el siglo de vida; este factor no pasa en absoluto desapercibido para el periódico. Un ejemplo significativo es el reportaje que se realiza sobre dos vecinas de Muga de Alba, una con los 100 años ya cumplidos y la otra a punto de alcanzar los 101. En el texto -que cuenta con el apoyo de una tribuna de opinión del corresponsal- se cuenta la azarosa vida de ambas, con una lucha constante para salir adelante. Con estas palabras, a nuestro juicio, se trata de incidir en la dignidad de estas dos mujeres anónimas, considerándolas unas heroínas de sus propias vidas ${ }^{101}$.

97 La Opinión-El Correo de Zamora (16-10-2012), pp. 20-21; y La Opinión-El Correo de Zamora (9-11-2012), p. 25.

98 La Opinión-El Correo de Zamora (14-2-2012), p. 24.

99 La Opinión-El Correo de Zamora (21-2-2012), p. 23.

100 La Opinión-El Correo de Zamora (4-6-2012), p. 32.

101 La Opinión-El Correo de Zamora (1-7-2012), p. 23. 
En los artículos de opinión también se aborda de manera habitual el envejecimiento de la población. Una de las principales firmas es, en este sentido, la del redactor jefe, Celedonio Pérez, responsable principal de los contenidos relacionados con las comarcas y el campo zamoranos. En sus textos acostumbra a hacer una defensa firme de la pervivencia de la sociedad rural, alertando sobre el vacío al que se enfrentan a menudo los pueblos pequeños. Hay uno de ellos que nos llama la atención muy por encima del resto, titulado "La foto" y publicado el 10 de octubre de 2012. Alude a la imagen que ilustraba la portada del diario el día anterior, en la que un grupo de vecinos de Abejera escuchaba atentamente a los técnicos de la Junta de Castilla y León que les explicaban cómo sería el proceso de concentración parcelaria en el pueblo ${ }^{102}$.

Para Celedonio Pérez, esta fotografía es "seguramente sin quererlo el autor [Chany Sebastián, el corresponsal en Aliste], una tesis doctoral sobre el ámbito rural zamorano". El redactor jefe destaca que la instantánea "ha captado lo que hay. Los jóvenes no se han ido de la fotografía, es que en la reunión no hubo jóvenes, no están, no viven allî”. De aquí se desprende la desazón de asistir al declive, no ya del pueblo de Abejera, sino del medio rural en general. Con todo, creemos que al mismo tiempo se elogia el instinto de supervivencia de, antes de dejar morir por completo la tierra, optar por concentrarla para que a quienes sigan labrándola les salga rentable.

\subsubsection{Niños y jóvenes: un escaso halo optimista}

Hay artículos que inciden en la vida joven que aún se respira en la comarca y, de forma implícita, pone en ella sus esperanzas de que algún día los procesos de emigración y alta mortalidad puedan invertirse o al menos mitigarse. Niños $\mathrm{y}$ adolescentes son un bien muy preciado y, por ello, cualquier actividad que se realiza con ellos se destaca en el periódico con un espacio significativo y un titular más o menos llamativo. La celebración del carnaval en Alcañices a la conmemoración del Día Forestal Mundial por parte de los alumnos de ESO y Bachillerato del instituto comarcal, pasando por una excursión de los alumnos de ESO de Tábara para conocer la biodiversidad de un río cercano, o el festival navideño de Ferreras de Abajo ${ }^{103}$.

Es habitual que se esté recalcando la necesidad de mantener población en edad escolar en la comarca, hasta de forma implícita. Una muestra clarísima de esto lo tenemos en la reseña que se hace a la visita de los alumnos más jóvenes del colegio de Muelas del Pan al Ayuntamiento de la localidad ${ }^{104}$. El

102 La Opinión-El Correo de Zamora (10-10-2012), p. 24.

103 La Opinión-El Correo de Zamora (19-2-2012), p. 28; La Opinión-El Correo de Zamora (22-3-2012), p. 22; La Opinión-El Correo de Zamora (29-5-2013), p. 26; y La Opinión-El Correo de Zamora (22-12-2012), p. 22.

104 La Opinión-El Correo de Zamora (27-3-2012), p. 23. 
texto dice que fueron al consistorio los alumnos más pequeños del centro, pero en la foto con el alcalde sólo aparecen siete niños, lo que da una idea del poco alumnado de este colegio y, en general, del resto de instalaciones escolares de la comarca. Meses más tarde, en junio de 2013, una fotonoticia recogió el acto de graduación de los alumnos de Bachillerato en el instituto de Alcañices. Hay 17 chicos y chicas en la fotografía, otra prueba de lo poco numerosas que son las capas más bajas de la pirámide demográfica ${ }^{105}$.

\subsection{El lobo: debate ante la controversia}

En la Sierra de la Culebra se encuentra la principal población de lobo ibérico de toda la península. La especie quedó en el pasado al borde de la extinción, arrinconada en este lugar poco accesible y sin apenas presencia humana. Sin embargo, en las últimas décadas ha proliferado de manera notable, lo que ha tenido como consecuencia negativa el aumento de los ataques a granjas bovinas y ovinas. Ante esto, hay abierto en la zona un complejo debate entre la preservación de la especie sin ataduras y el establecimiento de más medidas de control. En la polémica confluyen aspectos ecológicos y económicos; éstos, además, en una doble vertiente, dado que la presencia del lobo interfiere en un sector tan estratégico como la ganadería, pero ha traspasado su carácter de importantísimo valor natural para convertirse en un factor de atracción turística.

La Opinión-El Correo de Zamora es testigo de esta controversia y muestra todas las caras de la polémica. La de mayor impacto visual es la de los ataques a granjas; por ejemplo, vemos dos con pocos meses de diferencia en Carbajales de Alba, primero a una explotación bovina y más tarde a otra ovina ${ }^{106}$. Estos sucesos tienen siempre como respuesta la demanda de soluciones por parte de los ganaderos a las administraciones públicas ${ }^{107}$. Por otra parte, en distintos artículos de opinión se recogen todos los puntos de vista, con tribunas como la que defiende la protección de la especie como un recurso natural y económico de primer orden, asegurando que el lobo es el motivo de visita de casi la mitad de los turistas de la Sierra de la Culebra al cabo del año ${ }^{108}$.

Las distintas sensibilidades en torno al cánido se recogen también en un amplio reportaje que pone sobre la mesa el valor medioambiental del lobo, los intereses de los ganaderos, la postura de la administración autonómica e, incluso, el aspecto cinegético de la especie ${ }^{109}$. Pero además, hay espacio para el lado más etnográfico del asunto, con la presentación de un documental que recoge

105 La Opinión-El Correo de Zamora (21-6-2013), p. 22.

106 La Opinión-El Correo de Zamora (10-1-2012), p. 23; y La Opinión-El Correo de Zamora (3-5-2012), p. 24.

107 La Opinión-El Correo de Zamora (30-5-2012), p. 24; La Opinión-El Correo de Zamora (14-8-2012), p. 26; y La Opinión-El Correo de Zamora (6-9-2012), p. 20.

108 La Opinión-El Correo de Zamora (5-12-2012), p. 25.

109 La Opinión-El Correo de Zamora (28-1-2012), pp. 20-21. 
testimonios de vecinos de Aliste y Sanabria acerca de la compleja convivencia histórica con el lobo ${ }^{110}$; este artículo viene apoyado por una de las tribunas de Chany Sebastián, que aporta detalles como que "el cánido siempre ataca en contra del viento para evitar ser olfateado por los mastines".

En definitiva, desde las páginas de La Opinión-El Correo de Zamora se está poniendo sobre la mesa un asunto tan complejo como la presencia del lobo ibérico en la provincia y sus diversas consecuencias, tanto positivas como negativas. Creemos que el periódico hace una labor importantísima para generar debate al respecto, ya que expone todos los puntos de vista y da voz de forma directa a todo tipo de sensibilidades al respecto. Además, consigue llamar la atención de la Junta de Castilla y León, algo especialmente importante porque es quien tiene la competencia de encontrar una solución que satisfaga en la mayor medida posible a todas las partes.

\section{Conclusiones}

El espacio que conforman Aliste, Tábara y Alba es un territorio apenas habitado y muy envejecido, que por estar alejado de grandes núcleos urbanos y haber quedado al margen de los principales flujos de comunicación mantiene en la actualidad manifestaciones culturales y pautas sociales muy singulares. La comarca todavía sufre un cierto atraso socioeconómico como consecuencia de ese prolongado olvido, dado que la falta de población joven dificulta mucho el desarrollo de iniciativas emprendedoras que ofrezcan una alternativa de futuro atractiva. En este sentido, las deficiencias en las telecomunicaciones y en parte de las infraestructuras viarias, y la constante disyuntiva entre la falta de rentabilidad de muchos servicios y la necesidad de mantenerlos desde un punto de vista social se plantean como problemas muy graves, junto con el solo hecho de que cada vez hay menos habitantes y son cada vez más mayores.

Sin embargo, el territorio atesora un enorme potencial todavía por explotar en buena medida. En el campo económico, la ganadería bovina se perfila como un sector de futuro gracias a la calidad de sus carnes, aunque lleva el lastre de no tener aparejada una industria transformadora potente y la necesidad de apoyos para que estas tareas resulten rentables y compensen la dureza física de su mantenimiento. También la micología, siguiendo la misma pauta de ir de la mano de la transformación industrial, y con un rendimiento económico para los pueblos, presenta oportunidades. Asimismo, el secular aislamiento ha hecho que perviva un patrimonio cultural único, del que las mascaradas son su principal manifestación, aunque hay otros ejemplos notables como la Semana Santa de Bercianos de Aliste. Ese factor configura otro importantísimo potencial desde el punto de vista turístico, al que se unen elementos como el patrimonio monumental de localidades como Alcañices o Tábara y el valor natural

110 La Opinión-El Correo de Zamora (20-1-2012), p. 23. 
de espacios como la Sierra de la Culebra. Aquí, el controvertido lobo es tanto un dolor de cabeza para los ganaderos como una característica natural única y, por esta última razón, también un recurso turístico de primer orden. Esa difícil convivencia es, por lo tanto, tan imprescindible como necesaria del apoyo y seguimiento oportuno desde las administraciones superiores con competencias en la materia.

La Opinión-El Correo de Zamora recoge a diario todas esas demandas, iniciativas e inquietudes, actuando como una poderosa herramienta de difusión. El periódico es en estos momentos hegemónico en cuanto a prensa escrita en la provincia y tiene una elevadísima presencia social, tal y como muestran las cifras de ventas y lectores. Por lo tanto, tiene un notable poder de influencia, a pesar de radicar en un lugar tan poco poblado y que puede parecer tan poco trascendente como Zamora. No hay que olvidar que, como medio de referencia provincial que es, los ejemplares de este periódico llegan cada día a los despachos de instituciones como la Diputación y la Junta de Castilla y León, y que lo que reflejen sus páginas puede condicionar la acción de los dirigentes políticos, como así consideramos que ha sido en algunos casos. Creemos que esto es muy importante, sobre todo teniendo en cuenta que La Opinión-El Correo de Zamora marca ciertas distancias con el poder y se toma una posición claramente defensora de aquello que considera de interés para la provincia, como la mejora de infraestructuras, el mantenimiento de servicios o el desarrollo de ideas emprendedoras.

Por lo tanto, en el caso concreto de Aliste, Tábara y Alba, el periódico es la mejor herramienta de que las demandas ciudadanas lleguen hasta las instituciones, o que las iniciativas de tipo económico y social sean conocidas por los propios vecinos de la comarca y puedan calar entre la población. También creemos que es una forma muy efectiva de que ciudadanos de otras partes de la provincia de Zamora conozcan qué pasa en Aliste, qué se mueve allí, o, simplemente, que sepan que en Aliste pasa algo, que no es un territorio muerto, sino que tiene un tejido social activo a pesar de circunstancias negativas como la escasez de población, el envejecimiento y la lejanía de los centros de poder. Y que, además, tiene un potencial turístico y cultural interesante. Por ello, creemos que los distintos proyectos de desarrollo local que se llevan a cabo en la comarca encuentran un altavoz indispensable en las páginas del diario.

Vemos en La Opinión-El Correo de Zamora una implicación total con las iniciativas de desarrollo que surgen en el territorio, ya vengan forzadas por las circunstancias como en el caso de Abejera o partan de las inquietudes de los vecinos. Estimamos que el estímulo que se ofrece a todas ellas desde el periódico es fundamental, porque además de difundirlas entre los lectores les otorga un punto de seriedad y de consistencia que les puede servir de aval en un futuro. El estilo directo que se emplea en la redacción, sin barroquismos, y esa prudencial distancia respecto del poder hacen que 
nos encontremos ante un medio de comunicación muy vivo, fresco y profesional. Creemos que La Opinión-El Correo de Zamora es un periódico que siente vivamente el territorio y lo defiende por encima de cualquier otro aspecto, de una forma muy activa y sin victimismos, y que eso lo convierte en un elemento fundamental en el desarrollo de toda la provincia y en un caso merecedor de estudio.

BiBLIOGRAFÍA

DEL BARRIO ALISTE, José Manuel: Proceso de cambio y tendencias de futuro de la sociedad rural de Zamora. Implicaciones para el desarrollo rural del espacio fronterizo. Zamora, Fundación Rei Afonso Henriques, 1999.

DEL BARRIO ALISTE, José Manuel: Voces desde el oeste. Una radiografía provocadora de Zamora y sus gentes. Zamora, Monte Casino, 2002.

HORTELANO MÍNGUEZ, Luis Alfonso (coord.): Atlas de la raya hispanolusa. Zamora / Trás-os-Montes. Zamora, Diputación Provincial de Zamora, 2009.

- La vida en la frontera con Portugal. Valladolid, Dirección General de Estadística de la Junta de Castilla y León, 2010.

LÓPEZ GARCÍA, Xosé: Desafios de la comunicación local: guía práctica de la información en los ámbitos de proximidad. Sevilla, Comunicación Social Ediciones y Publicaciones, 2004.

MARTÍNEZ PUCHE, Antonio; PÉREZ PÉREZ, David; SANCHO CARBONELL, Isabel: Eines per al desenvolupament local / Herramientas para el desarrollo local. Cocentaina, CEDER Aitana y Universidad de Alicante, 2000.

MAYA FRADES, Valentina: La mujer rural en la provincia de Zamora. Salamanca, Fondo Social Europeo-Diputación de Zamora-Ministerio de Administraciones Públicas-Atalanta (Promoción de de Empleo para la Mujer Rural), 2004.

MÉNDEZ PLAZA, Santiago: Costumbres comunales de Aliste. Madrid, Real Academia de Ciencias Morales y Políticas, 1900. Reimpresión de Editorial Semuret (Zamora) y Ayuntamiento de Riofrío de Aliste, 2002, prologada por Juan Ignacio Plaza Gutiérrez y Luis Alfonso Hortelano Mínguez.

PÉREZ RAMÍREZ, Bartolomé; CARRILLO BENITO, Emilio: Desarrollo local: manual de uso. Madrid, ESIC y Federación Andaluza de Municipios y Provincias, 2000.

PINELO TIZA, António: Mascaradas e Pauliteiros. Etnografia e educaçao. Lisboa, Eranos, 2013.

PLAZA GUTIÉRREZ, Juan Ignacio: Aprovechamiento agrario y usos del suelo en la penillanura zamorana. La Tierra de Aliste. Salamanca, Universidad de Salamanca, 1989. 
PLAZA GUTIÉRREZ, Juan Ignacio: Estructura del espacio geográfico y políticas territoriales en la Tierra de Aliste (Zamora). Salamanca, Junta de Castilla y León-Universidad de Salamanca, 1990.

SÁNCHEZ ZURRO, Domingo: Geografía de Castilla y León. Valladolid, Junta de Castilla y León-Ámbito ediciones, 2008.

SEBASTIÁN, Chany: Mascaradas. Antruejos de Zamora y Trás-os-Montes. Alcañices, Federación Comarcal de Asociaciones Culturales de Aliste, Tábara y Alba, 2004.

SEISDEDOS ROBLES, Juan: Estructura y perspectivas de desarrollo económico de la provincia de Zamora. Zamora, Consejo Económico Sindical Provincial, 1971.

- Territorio y desarrollo local, revista del Departamento de Política Territorial e Interior del Gobierno de Aragón. Zaragoza, 2007. 